\title{
Buyers' and Sellers' Agents in the Housing Market
}

\author{
MARK BAGNOLI \\ Finance Department, Indiana University School of Business \\ NAVEEN KHANNA \\ School of Business, University of Michigan
}

\begin{abstract}
We explain why buyers in the housing market use an agent employed by the seller. Such agents reduce buyers' search costs so that more buyers search a particular house. This increases the probability of the sale of the house and possibly also its selling price. However, since the selling price increases, if at all, by less than the fee paid by the seller to the agent, both buyers and sellers are better off. We identify two characteristics that give rise to sellers' agents and show that markets that do not have such agents are missing at least one of these characteristics.
\end{abstract}

Keywords: Real estate brokerage, housing search, sellers' agents

\section{Background and theory}

The objective of this article is to apply search theory and the theory of markets with imperfectly informed consumers to explain the role of agents in the housing market. We concentrate specifically on those real estate agents who are employed by the sellers to assist the buyer in searching for a house. We refer to such agents as sellers' agents. ${ }^{1}$ It is not at all clear why the agent who helps the buyer search for a house should be employed by the seller. This agent's primary role is to match a buyer with an already listed house. An agent employed by a buyer should easily be able to duplicate this role. Since a parallel institution of buyers' agents (agents employed by the buyer) has not emerged as a significant force, one is left to wonder why sellers' agents are so desirable that buyers' agents cannot replace them.

This question becomes even more perplexing when one considers the legal implications of such an arrangement. By using sellers' agents, the buyer works with an agent who is legally responsible to the seller. Thus, the role of sellers' agents appears to be in conflict with the results in the principal-agent literature which suggests that a buyer should be able to do better by employing the agent directly. ${ }^{2}$ Therefore, we hypothesize that there is some countervailing advantage to both buyers and sellers from working with such a contract. In this article, we identify one reason why sellers employ these agents and why buyers accept such an arrangement.

To begin with, searching for a house is a costly activity for buyers. They must identify the houses for sale, and get a reasonable amount of information about the characteristics of neighborhoods and houses. There is a need for personal inspection of houses and, in 
addition, there may be a need to hire professionals (appraisers, lawyers, etc.) to help in the process. Together, these force a buyer to incur what we will refer to as search costs.

The presence of such costs results in only some potential buyers searching. Agents, either buyers' or sellers', serve to reduce the extent of these costs and thus increase the number of searchers. Hence, employing agents leads to higher expected profits for the seller. When agents are in part compensated by the seller, as with sellers' agents, buyers' search costs get further reduced by the amount of this compensation. This increases the number of searchers and the sellers' expected profits by even more. An important point to note is that the increase in expected profits does not come necessarily from a higher selling price of a house, but from an increased probability of sale. For this reason the price of a house rises (if at all) by less than the cost the seller incurs to employ the agent. ${ }^{3}$ Thus, the outcome can be a pareto improvement.

For our model, we assume that there are a large number of buyers and sellers. Based on their preferences, their priors about the types and prices of houses in the market, and their search costs, buyers choose whether to search a particular house. The search results in their learning more about the particular house. With this information, the buyer determines his/her reservation price for the house. Hence we will refer to search as learning one's reservation price.

Buyers search whenever the expected marginal benefits exceed the marginal costs. Clearly, a reduction in search costs, ceteris parabus, leads to an increase in the number of searchers. This supports our earlier assertion that agents, whether buyers' or sellers', increase the amount of search. ${ }^{4}$

A seller knows about the distribution of the buyers' reservation prices, though not about any particular buyer's reservation price (even after the buyer has searched). He/she also observes the number of buyers who search his/her house, and he/she takes this information into account when setting the selling price. Thus, the seller faces a gamble. The higher the selling price, the larger are the profits in the event the house sells, but the probability of sale is lower. As an expected profit maximizer, he/she sets the price only after taking into account the effect on the probability that the house will sell. For example, if he/she sets the price higher than all the buyers' reservation prices, then the house will not sell, and profits will be zero. As he/she lowers the price, the probability of selling rises, and so he/she trades off lost revenues for a higher probability of sale.

Finally, we "test" our explanation by asking whether the factors that we have identified as important-expensive search, need for personal inspection, and the lack of less expensive alternative means for reducing the buyers' search costs - are present in markets with analogous institutions and are absent in markets without such institutions. Examples of analogous institutions include headhunters in the market for corporate executives, independent insurance agents, travel agents, and salespeople. We will argue that all these markets exhibit the factors we believe are important. Markets that do not have analogous institutions include those for most consumer products, such as toiletries or food, and those for collectibles, such as rare coins and masterpieces. In these latter markets we believe that at least one of the factors identified is missing. For example, notice that for a product such as toothpaste, the buyer's personal inspection is necessary. However, the use of selling agents does not appear to be the least expensive way to reduce the buyers' search costs, while advertising (free samples) is. 
The article is organized as follows. In the next section we provide an example to demonstrate that a seller's expected profits increase with the use of a seller's agent. ${ }^{5}$ In section three we look for analogous institutions and factors in other markets. This part is followed by a conclusion.

\section{Buyers' and sellers' agents}

We explain our intuition through a simple example. Although we assume that many houses are for sale, we concentrate on one seller's problem. The seller is assumed to be riskneutral, and chooses the selling price to maximize his/her expected profits from sale. For simplicity, we normalize the seller's reservation price for the house to be zero. We then look at the seller's decision (selling price) in three different environments: without agents, with buyers' agents, and with buyers' agents and a seller's agent.

The information structure of our model is as follows: buyers do not learn about all the relevant characteristics of a house unless they personally inspect it. To keep the analysis simple, we assume that buyers will decide only whether to search or not, not how much. Their personal search will determine their actual reservation price of the house. Prior to search they know only the distribution of house types and the distribution of prices. They make their decision to search a particular house based on their priors and their search costs.

We assume that there are three potential buyers $(b 1, b 2$, and $b 3)$ for a particular house. For the sake of expediency, we shall assume they are all male. The seller knows the characteristics of his/her house and so can compute the distribution of buyers' reservation prices for his house, given the buyers' search decisions. We assume that the seller's prior beliefs, before he sees any buyer searching, are that each buyer's reservation price for his house is uniformly distributed on [0,200]. We capture the buyers' search decisions as follows: without agents, only $b 1$ is willing to search, and if he does, his reservation price is at least 100. Therefore, if the seller observes $b 1$ searching his house, he updates his priors about bl's reservation price to be uniformly distributed over [100,200].

With buyer's agents, search costs are reduced by $\$ 2$, and this makes both $b 1$ and $b 2$ willing to search. If $b 1$ searches, then his reservation price is at least 98 , and if $b 2$ searches, his reservation price is at least 99 . Note that $b$ 's lowest reservation price for the house falls when there is a reduction in the search costs. The presence of a seller's agent also reduces search costs by $\$ 2$. However, in this case the seller pays a portion of the agent's fees, say, \$1, out of his own pocket, and this reduces the up-front search costs and so also the minimum reservation prices. ${ }^{6}$ This allows $b 3$ also to start searching. Hence, all three buyers search if their reservation prices are at least 97,98 , and 99 , respectively.

\subsection{SCENARIO 1: There are no agents}

When only one buyer chooses to search, the house will be sold if (1) there is search, and (2) if the price fixed by the seller is below the reservation price of the buyer. Recall that the buyer learns his reservation price after he has searched the house. We solve this problem in two steps. First, we compute the equilibrium price that the seller will charge after 
he sees a buyer searching his house. We then multiply this by the probability that the house will be searched. This gives us the expected profits of the seller.

Once the seller observes a search, he concludes that this buyer's minimum reservation price for his house is $\mathbf{1 0 0}$. Thus the probability that the buyer's actual reservation price is below some price, $p$, in the range of 100 to 200 is, $(p-100) / 100$. Thus the probability of sale is $1-(p-100) / 100$, and the seller chooses the $p$ which solves:

$$
\max p(1-(p-100) / 100)
$$

The $p^{*}$ that solves this is $\$ 100$. Since the probability that the potential buyer searches is $100 / 200$, the seller's expected profits are $\$ 50$.

\subsection{SCENARIO 2: There are buyers' agents who reduce search costs by $\$ 2$}

Case 1. Only $b 1$ uses an agent.

If $b 1$ searches, he will indicate to the seller that his minimum reservation price for the house is $\$ 98$. Also, since $b 2$ does not use an agent he does not search. Thus the seller solves for $p$ in the following manner:

$$
\max p(1-(p-98) / 102)
$$

The $p *$ that solves this is still $\$ 100$, and the expected profits are $100[1-(100-$ 98) $/ 102](102 / 200)=\$ 50$.

Case 2. Only $b 2$ uses an agent.

Since $b 2$ 's search costs are now reduced, he may also choose to search this house. Two situations can arise. Either both buyers will search the house or only one of them will.

Case $2 a$. Both $b 1$ and $b 2$ (now with agent) search the house.

Now, $b 2$ 's reservation price is reduced to $\$ 99$, while $b 1$ 's remains at $\$ 100$. The seller observes both buyers searching and picks a price, $p$. The probability that both $b 1$ and $b 2$ have their actual reservation prices below this $p$ is $[(p-100) / 100][p-99) / 101]$. Thus the probability of sale at price $p$ is 1 less this probability. The seller chooses $p$ to:

$$
\max p[1-[(p-100) / 100][(p-99) / 101]]
$$

The $p *$ that maximizes this is $\$ 133.12$.

Case $2 b$. When only one buyer searches the house (note that the seller cannot distinguish between $b 1$ and $b 2$ ), the seller sets $p=100$ as in case 1 . Thus the expected profits of the seller are as follows:

In case 1 , they are $\$ 50$.

In case 2 , they are $(100 / 200)(101 / 200)(133.12)[1-\{(133.12-100) / 100\}\{133.12-99) / 101\}]$ $+(100 / 200)(99 / 200) 100+(100 / 200)(101 / 200) 100(1-1 / 101)=\$ 79.20$. 
The first term of the expression is the expected profit when both $b 1$ and $b 2$ show up. The second term is the expected profit when only $b 1$ searches, while the third is the expected profit when only $b 2$ searches.

Thus, when one of the buyers works through an agent, and it is $b 2$ with probability $a$ $>0$, the total expected profits to the seller are: $a(79.2019)+(1-a) 50>50$. Thus the presence of even one buyer's agent increases the expected returns of the seller.

\section{Case 3. Both buyers hire agents.}

Now, either both search or only one searches and the seller sets a selling price on that basis.

Case 3a. Both buyers search.

The minimum reservation price of $b 1$ is now 98 , and that of $b 2$ is 99 . Thus the seller solves the following:

$$
\max p[1-[(p-98) / 102][(p-99) / 101]] .
$$

The $p^{*}$ that solves this is $\$ 132.84$.

Case $3 b$. When only one searches, and it is $b 1$, the seller solves for $p$ in the following manner:

$$
\max p(1-(p-98) / 102) .
$$

This gives $p^{*}$ of $\$ 100$.

Case $3 c$. When only one searches, and it is $b 2$, the seller solves the following:

$$
\max p(1-(p-99) / 101) .
$$

and the $p^{*}$ is again $\$ 100$.

Thus the seller's expected profits when both buyers hire agents are: $(102 / 200)(101 / 200)(132.84)(1-(34.84 / 102)(33.84 / 101))+(102 / 200)(99 / 200)(100)(100 / 102)$ $+(98 / 200)(101 / 200)(100)(100 / 101)=\$ 79.55$. Thus the seller is better off when buyers work through agents.

\subsection{SCENARIO 3: There are both buyers' agents and one seller's agent}

Next we introduce a seller's agent. This agent also reduces the buyers' search cost by \$2. However, on top of that, the seller pays a fee of $\$ 1$ to his agent. So, the buyer who works through this agent has his upfront search costs reduced by $\$ 3$. This further reduces the minimum reservation price for which a buyer searches, that is, to $\$ 97$ for $b 1$, if he is the one to use this agent, to $\$ 98$ for $b 2$, if he does, and to $\$ 99$ for $b 3$, if he does.

Below, we analyze three different cases, when $b 1$ employs a seller's agent while the others work with buyers' agents, or when either $b 2$ or $b 3$ employ the seller's agent. When either $b 1$ or $b 2$ works through the seller's agent, it increases the probability that both will search 
this house; however, it does not result in more potential buyers searching for houses. That happens only if $b 3$ works through the seller's agent because only in this case is $b 3$ willing to search.

Case $1 . b 1$ uses the seller's agent and $b 2$ uses a buyer's agent.

When both $b 1$ and $b 2$ search, the seller sells to $b 1$ only if he is unable to sell to $b 2$ because this enables him to avoid paying the additional dollar out of his own pocket. He solves for the $p$ that solves:

$$
\max (p-1)[(200-p) / 103][(p-99 / 101)]+p(200-p) / 101 .
$$

The first term of the expression represents the probability that the seller will sell to $b 1$, which is [ $(200-p) / 103][(p-99) / 101]$, times what he receives, that is, $p-1$. The second term is his expected return if he sells to $b 2$. The optimal $p *$ is $\$ 132.5928$.

When only one searches, and it is $b 1$ through the seller's agent, the seller's problem is:

$$
\max (p-1)(200-p) / 103
$$

The $p *$ that solves this is $\$ 100.5$. The point to note is that even though the seller is charging a higher price than when the buyer comes with his own agent, the price increase is less than the dollar fee the seller will be paying to the agent out of his own pocket.

When only one searches, and it is $b 2$ with his own agent, the problem is similar to equation (6) and the optimal $p$ is again $\$ 100$.

The expected value to the seller when $b 1$ uses the seller's agent is:

$$
\begin{aligned}
& (103 / 200)(101 / 200)[\{132.5928-1)(67.4072 / 103)(33.59 / 101)\}+(132.5928)(67.4072 / 101)] \\
& (103 / 200)(99 / 200)(99.5)(99.5 / 103)+(97 / 200)(101 / 200)(100)(100 / 101)=\$ 79.5188
\end{aligned}
$$

Case 2. $b 2$ uses seller's agent and $b 1$ uses buyers' agents.

Again, $b 3$ will not search, and the problem is very similar to case 1 . Not surprisingly, the optimal prices for when both search and when only one searches are also very similar. The $p^{*}$ when both search is $\$ 133.2557$. When only $b 1$ searches with a buyer's agent, the $p^{*}$ is $\$ 100$, and when only $b 2$ searches through with the seller's agent, then $p *$ is $\$ 100.5$. $p *$ is higher when both search and $b 2$ uses the seller's agent than when $b 1$ uses the seller's agent because there is a difference in the minimum reservation prices of $b 1$ and $b 2$. The total expected returns to the seller in case 2 are $\$ 79.2158$.

Case 3. $b 3$ uses the seller's agent and both $b 1$ and $b 2$ use buyer's agents.

Now it is possible that all three buyers search. Since the seller prefers to sell to $b 3$ only when neither $b 1$ nor $b 2$ finds his selling price acceptable, the seller solves for $p$ in the following problem.

$$
\begin{gathered}
\max p[1-(p-99)(p-98) /(101 * 102)]+ \\
(p-1)[(200-p)(p-98)(p-99) /(101 * 101 * 102)] .
\end{gathered}
$$


The expression $1-(p-99)(p-98) /(101 * 102)$ represents the probability that at least one of either $b 1$ or $b 2$ will have his reservation price above $p *$. In this case the seller gets all of $p^{*}$. The second expression gives the probability that the seller can sell only to $b 3$ in which case he gets only $p-1$ as he pays $\$ 1$ to the agent out of his own pocket.

Equation (10) is a cubic in $p^{*}$. An approximate solution for it is $\$ 145$. This represents the $p^{*}$ the seller will set if he sees all three searching, and his expected value is (145)[1 - $(46 * 47) /(101 * 102)]+(144)[(55 * 46 * 47) /(101 * 101 * 102)$, which is $\$ 131.47$.

When only two search, and they are $b 1$ and $b 2$ (both with buyers' agents), then the problem is the same as in equation (4) with the $p^{*}$ of $\$ 132.84$. If they are $b 1$ and $b 3$, then $p^{*}$ is $\$ 132.9826$; if they are $b 2$ and $b 3, p^{*}$ is $\$ 132.92 .^{7}$ The expected value to the seller when only two search is approximately $\$ 117.7$.

When only one appears, then as before, if it is either $b 1$ or $b 2, p *$ is $\$ 100$, and if it is $b 3, p^{*}$ is $\$ 100.5$. The expected value to the seller when only one searches is $\$ 98$. Thus the total gains to the seller under case 3 are $\$ 100.1$.

We can also estimate the total expected gains to the seller when there is a seller's agent in addition to the buyers' agents. These are:

$$
c(79.5188)+d(79.2158)+e(100.1),
$$

where $c$ is the probability that $b 1$ uses the seller's agent, $d$ the probability that $b 2$ does, and $e$ that $b 3$ does.

Since the expected return to the seller is $\$ 79.55$, when there are buyers' agents, but no seller's agent, the seller prefers an environment with a seller's agent for all $e$ for which equation (11) exceeds $\$ 79.55$. Since this certainly occurs for $e>0.016$, the seller is better off with a seller's agent whenever the probability that $b 3$ will work through this agent is above 1.6 percent. Since, a priori, there is no reason to expect that $e$ is significantly different from 33 percent, the seller would be better off with a seller's agent.

These particular scenarios were chosen specifically to show the following: by comparing scenario 1 to scenario 2 (cases 1-3), one sees that when buyers' agents are available, equilibrium cannot have no agents used. With no agents, the seller's expected profits are 50 and the price is 100 . If $b 1$ hires an agent (scenario 2, case 1), the selling price and the seller's expected profits are unchanged, while search costs decrease by $\$ 2$. Hence $b 1$ is better off. The same reasoning shows that, relative to the no-agent case, $b 2$ is better off, too.

Next, we computed scenario 2, case 3 . This gives us a baseline case from which to evaluate the use of seller's agents. Scenario 2, case 3, is the outcome when all buyers have access to a buyer's agent. Notice that this solution (an equilibrium if seller's agents are prohibited) leaves the seller with expected profits of $\$ 79.55$. Notice also that price is higher than $\$ 100$ if both buyers end up searching the house. If this occurs with relatively low probability, the search-cost savings will outweigh this effect, and all are better off. If the probability is higher, then the buyers are worse off than if buyers' agents are unavailable. However, just as in the standard Prisoner's Dilemma game, the equilibrium has them both choosing to use buyer's agents. ${ }^{8}$

Comparing scenario 2 , case 3 , with scenario 3 shows that, if a seller can hire a seller's agent, he will do so. That is, in a market with buyers' agents, the seller employing a seller's agent can increase his own profits and also benefit the buyer who uses the agent. Hence, 
seller's agents must be present in the equilibrium. We do not compute the equilibrium when sellers agents are available to all because that alters the whole distribution of prices in such a way that our simplifying assumptions are no longer valid. Since our point is to show that seller's agents must be used, we accomplish our goals most directly by avoiding these extraneous details.

In conclusion, what we have shown is that, when agents reduce buyers' search costs, the sellers' expected profits go up, both because of a greater probability of sale and, on occasion, because they can raise their selling price. When sellers also pay a portion of an agent's fees (that is, hire a seller's agent), their profits go up even further. This increase in profits is due not to an increase in the selling price (since the increase is less than the seller's payment to the seller's agent) but because of a still higher probability of selling the house.

\section{Other similar markets}

There are basically two methods for evaluating the reasonableness of our explanation for the existence of sellers' agents in the housing market. The first is to analyze the factors that drive the result and make a judgment about their importance. The second is to take the explanation and see if the factors that it relies on are present in other markets with analogous institutions and not present in markets without these institutions.

\subsection{Analogous institutions}

Examples of analogous institutions include head-hunters in the market for corporate executives, independent insurance agents in insurance markets, and travel agents who assist in vacation planning. Another example is salespersons who provide customers with product information. Such products could be consumer goods such as a stereo or intermediate goods like those sold by the seller's traveling sales agent. We believe that the features we have identified as important for our explanation are present in each of these cases.

Each of these markets is characterized by the buyer's need to investigate the "product" personally, and by the fact that the search costs are sunk. In each of these markets, the use of the "seller's agent" appears to reduce the buyer's search costs.

In the market for corporate executives, the need to investigate the job personally is obvious, as is the fact that the buyer's search costs are sunk. The headhunter reduces the executive's direct search costs by permitting the executive to avoid contacting firms that are not hiring and indirect search costs because of the job-seeker's general unwillingness to have his current employer know that he is seeking another job.

Independent insurance agents are essentially identical to the selling agent in the real estate market in that they reduce the buyer's search costs by allowing him to learn the cost of insuring through a variety of different companies. Travel agents reduce the buyer's search costs by acquiring the information about the different plans as well as providing him with information about the different locales. Salespeople that provide information (including, for example, allowing the buyer to test products such as stereo equipment) reduce the costs of search for the buyer. 
In each of these cases, the buyer must also "self-investigate," in the sense that the information desired is generally not the same for every buyer. Personal preferences concerning vacation spots, quality of sound, or insurance needs differ sufficiently to make communicating this information by means other than personal investigation prohibitively expensive.

Most markets do not have an institution analogous to selling agents. Examples range from many consumer goods, such as toiletries and food, to rare coins or masterpiece paintings. Each fails to have at least one of the features that we have identified as important for the presence of such an institution. For most consumer products, self-investigation helps to determine some of the product's characteristics - for example, the taste of toothpaste or food. However, it appears that the sellers choose a less expensive means of reducing the buyer's search costs. That is, they provide free samples either in the mail or at the grocery store. Also, for many products of this sort, the search costs are quite low. (It is very unlikely that one will dislike the taste of a new toothpaste so much that it will remain unused. Hence the "search" costs are simply the loss in utility from not having the better tasting toothpaste.) Since these search costs are already quite low, the impact of reducing them is probably small. Unlike these examples, rare coins, masterpiece paintings, and other similar items, which are predominantly desired for investment purposes, do not appear to require self-investigation.

Hence, this brief examination of some marketplace examples seems to support our explanation for the existence of an institution such as selling agents in real estate markets. When the features that we identified - the need for costly self-investigation and the lack of less expensive means for reducing the buyer's search costs - are present, such institutions are also present. When at least one of the features is missing, so is the institution.

\section{Summary}

In this article, we explain why buyers in the housing market use an agent employed by the seller. Our explanation is that selling agents, by reducing the buyer's search costs, increase the expected profits of the sellers by increasing the number of buyers who search. As long as the cost of providing this service is smaller than the gain, the seller has an incentive to employ a selling agent. We identify two important characteristics of a market that lead to the use of sellers' agents: (1) the description of the house can (feasibly) be communicated to the buyer only through self-investigation, and (2) the cost of this activity is nontrivial and sunk.

We also asked whether the factors that we had identified as important were present in markets with analogous institutions and absent in markets without an analogous institution. We considered a number of examples, including the head-hunters in the market for corporate executives, independent insurance agents, travel agents, and salespeople, and argued that the factors were present in each of these markets. We also considered examples of markets without such institutions such as markets for consumer goods and markets for collectibles. In each of these, at least one of the factors was not present. These considerations lead us to believe that we have identified some of the important factors that result in the formation of institutions like sellers' agents. 


\section{Acknowledgments}

We would like to thank Ted Bergstrom, Larry Blume, Charlie Brown, Phil Howrey, Saul Hymans, Roger Kormendi, Joe Machak, Scott Masten, Greg Niehaus, Ron Singer, Ted Snyder, Jerry and Marie Thursby, and Hal Varian for helpful discussions. We also thank two anonymous referees and the editor, Dennis Capozza, for their insights. Special thanks to Margaret Doneen and Marsha Majors for helping us to understand this problem from the selling agent's point of view. Of course, we remain responsible for any errors.

\section{Notes}

1. Throughout this article, we ignore the agent who lists the house. This agent, referred to as the listing agent, performs a well-understood role for the seller.

2. See, for example, Grossman and Hart (1983) and Holmstrom (1979).

3. This is consistent with the findings of Frew and Jud (1987) and Doiron and associates (1985) that, through higher prices, the seller passes on to the buyer only one-third to one-half of the commission paid to the agents.

4. We realize that both the number of searchers and the amount of search by each searcher rises when search costs fall. We will focus on just the increase in the number of searchers so our points can be more easily made.

5. The general analysis is available in Bagnoli and Khanna (1988).

6. We will show that this payment of $\$ 1$ does not get translated to a selling price higher by $\$ 1$ over when there are only buyers' agents. Thus, the assumption that more buyers search will turn out to be a natural one.

7. Since $b 1$ and $b 2$ are indistinguishable here, and since the probability that the $b 1$ is the buyer with the buyer's agent is $102 / 102+101=1 / 2$, the optimal price is approximately $\$ 132.95$.

8. To do justice to this part, the effect of agents on the intensity of the buyers' search must be introduced. This will measure the benefits to buyers from better matches with houses. However, this will make the example intractable, and is beyond the objectives of this article.

\section{References}

Bagnoli, M. and Khanna, N. "A Note on Why Buyers Are Represented by Sellers' Agents When Buying a House," Working paper, University of Michigan, 1988.

Diamond, P. "A Model of Price Adjustment," Journal of Economic Theory (1971).

Doiron, J., Shilling, J. and Sirman, C. "Owner Versus Broker Sales: Evidence on the Amount of the Brokerage Commission Capitalized," Real Estate Appraiser and Analyst (1985).

Frew, J. and Jud, D. "Who Pays the Real Estate Broker's Commission?" Research in Law and Economics (1987).

Grossman, S. and Hart, O. "An Analysis of the Principal-Agent Problem," Econometrica (1983).

Holmstrom, B. "Moral Hazard and Observability," Bell Journal of Economics (Spring 1979). 